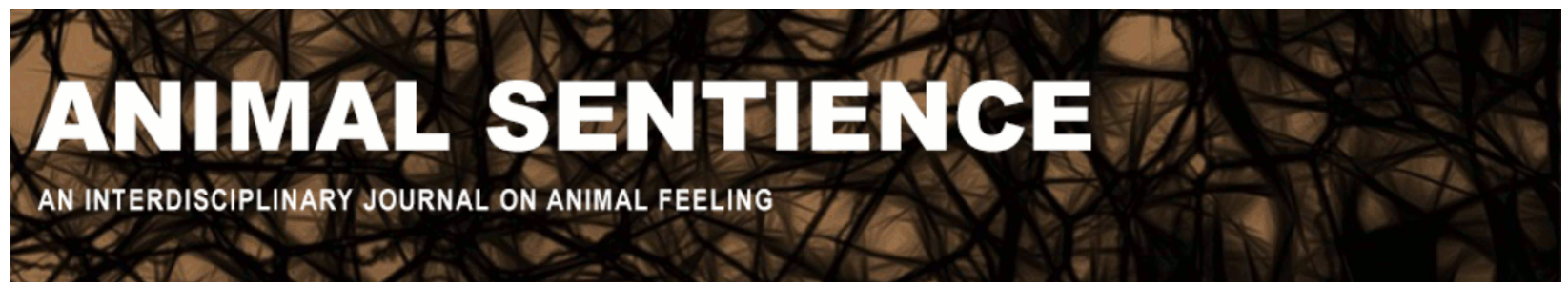

Pereira, Alfredo, Jr. (2017) Sentience in living tissue. Animal Sentience 13(5) DOI: $10.51291 / 2377-7478.1235$

Date of submission: $2017-10-28$

Date of acceptance: 2017-10-31

(c) (i)




\title{
Sentience in living tissue
}

Commentary on Woodruff on Fish Feel

\author{
Alfredo Pereira, Jr. \\ Institute of Biosciences \\ São Paulo State University (UNESP)
}

\begin{abstract}
I agree with Woodruff's concept of sentience but must disagree about what he proposes as the biological correlates of feeling. Based on the interpretation of brain function originally presented by Camilo Golgi, I assume that feelings are instantiated by hydro-ionic waves in living tissue. From this viewpoint, the anatomical, physiological and behavioural criteria of Woodruff would not be necessary to argue for sentience in fish.
\end{abstract}

\footnotetext{
Alfredo Pereira, Jr., Professor of Philosophy of Science, Institute of Biosciences, State University of São Paulo, does research on philosophy of neuroscience and consciousness. He has developed a philosophical theory called "TripleAspect Monism," and written and edited around two hundred publications.

www.researchgate.net/profile/Alfredo_Pereira_Junior
}

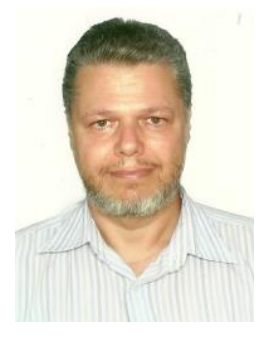

Michael Woodruff (2017) argues for the existence of conscious activity in ray-finned fishes of the teleost subclass. His argument is based on the neural organization of their nervous system; a neural circuit involving the optical tectum and the pallium would be sufficient to support that "fish feel."

The concept of sentience as "the minimal capacity to have subjective experience of the qualities associated with external and internal sensations, as well as affective and motivational states for phenomenal consciousness," and the reference to Allen and Trestman (2016), are very close to the concept of consciousness and feeling I have proposed (Pereira, Jr., 2013). This conceptual convergence is rare in consciousness studies. However, we do not seem to agree on the biological correlates of sentience.

The "Neuron Doctrine," implicit in the Cambridge Declaration on Consciousness (Low et al., 2012) and possibly also in Woodruff's expert reasoning (for instance, when he refers to neuron firing rates as indicating mental activity), implies that sentience requires a specific kind of neuronal architecture that can represent external and internal patterns accurately, to guide selective attention and to drive adaptive behavior. Instead of that assumption, I propose that sentience - at least for affective and motivational states, which are the focus of the paper - is based on hydro-ionic waves (see Pereira, Jr., 2017) in living tissue, generating graded electric potentials that can be found in practically all animal species, and also in plants.

The question of "tissue versus neuronal activity" as the biological substrate of mental functions began in 1906, when the Nobel Prize in Physiology or Medicine was awarded jointly to Camillo Golgi and Santiago Ramón y Cajal for their work on the structure of the nervous system. The first Nobelists received equal recognition by the scientific community, but their theoretical approaches to mental function were different. Golgi emphasized the 
structure of neural tissue (including neurons, glia and extracellular components) as carriers of mental functions, while Ramon y Cajal elaborated on the "Neuron Doctrine," assuming that the neuron was the structural and functional unit of the brain/mind. Cajal's doctrine has dominated neuroscientific thought for more than a century.

The emphasis on neurons became critical after McCulloch and Pitts's (1943) logical calculus based on action potentials, inspiring the creation of machines endowed with artificial intelligence. The success of these machines in several tasks, such as chess-playing, gave rise to the myth that the improvement of their intelligence, based on mechanical processing using a binary code, could result in artificial consciousness. The corresponding myth in the cognitive neurosciences has been that conscious activity is based on patterns of neuronal firing and synaptic connectivity in complex circuits and/or special regions of the brain.

Taking into consideration the existence of alternative ways of conceiving the biological correlates of mental function, is the detailed discussion of fish anatomy and physiology developed by Woodruff really needed for the argument in favor of fish sentience? In the model of sentience I have proposed, following Golgi's approach, the answer is negative. The biological correlate of elementary sentience is proposed to be a phenomenon that occurs in practically all kinds of living tissue, from the plant syncytium to the human astroglial network (a review of astroglial function in the human brain can be found in Pereira, Jr., and Furlan, 2010).

In a previous commentary in this journal, Woodruff (2016) argued against a cellular basis of sentience (Reber, 2016, 2017). His argument was that sentience has no explanatory power regarding the behavior of unicellular living systems. In the fish species here discussed, he claims that "one requirement is that the visual world be accurately represented in the tectum" and that sentience is also necessary for selective attention: "if sentience did not exist, then the processes of selective attention would have no work to do" (Woodruff, 2017). This is an excellent argument, but misses one aspect of the problem: the "animal feel," considered as an affective state, is a phenomenal experience that does not depend on accurate representations, selective attention or adaptive control of behavior. For example, we have introspective evidence that - contrary to the assumption of LeDoux (2012) feeling pain does not require a previous representation of pain. This introspective evidence is not contradicted by another piece of introspective evidence: we can attempt to represent pain a posteriori (for instance, interpreting it as "tooth pain"). In this case, the lived experience of pain is (fortunately) only partially captured by the representation.

From the above considerations, I conclude that sentience does not depend on mental representations, selective attention or adaptive control of behaviour: sentience comes first (both phylogeneticallly and phenomenologically) and motivates them. We interpret incoming signals and represent them according to our feels; we direct our attention according to motivations defined by our current affective states, and we act in the environment to maximize our good feels. Therefore, it is conceivable that all multicellular living systems able to generate a hydro-ionic wave (measurable as a graded electric potential) can experience the feels proper to their species, even if they do not have cognitive capacities to produce accurate representations, to exert selective attention or to elaborate on motor plans. 


\section{References}

Allen, C. \& Trestman, M. (2016) Animal consciousness. In E. N. Zalta (Ed.), The Stanford Encyclopedia of Philosophy (Winter Edition).

LeDoux, J. (2012) Rethinking the Emotional Brain. Neuron 73, 653.

Low, P., Panksepp, J., Reiss, D., Edelman, D., Van Swinderen, B. \& Koch, C. (2012) Cambridge Declaration on Consciousness. University of Cambridge.

McCulloch, W.S. \& Pitts, W. (1943) A logical calculus of the ideas immanent in nervous activity. Bulletin of Mathematical Biophysics 5, 115-133.

Pereira, Jr., A. \& Furlan, F. A. (2010) Astrocytes and human cognition: Modeling information integration and modulation of neuronal activity. Progress in Neurobiology 92, 405-420.

Pereira, Jr., A. (2013) Triple-aspect monism: A conceptual framework for the science of human consciousness. In A. Pereira, Jr., \& D. Lehmann (Eds.), The Unity of Mind, Brain and World: Current Perspectives on a Science of Consciousness. Cambridge University Press, Cambridge, UK, pp. 299-337.

Pereira, Jr., A. (2017) Astroglial hydro-ionic waves guided by the extracellular matrix: An exploratory model. Journal of Integrative Neuroscience 16, 1-16.

Reber, A. S. (2016) Caterpillars, consciousness and the origins of mind. Animal Sentience 11(1)

Reber, A. S. (2017) What if all animals are sentient? Animal Sentience 16(6)

Woodruff, M. (2016) Bacteria and the cellular basis of consciousness. Animal Sentience 11(2)

Woodruff, M. L. (2017) Consciousness in teleosts: There is something it feels like to be a fish. Animal Sentience 13(1) 


\section{ANIMAL CONSCIOUSNESS}

On November 17-18, 2017, the NYU Center for Mind, Brain and Consciousness, the NYU Center for Bioethics, and NYU Animal Studies will host a conference on Animal Consciousness.

This conference will bring together philosophers and scientists to discuss questions such as: Are invertebrates conscious? Do fish feel pain? Are nonhuman mammals self-conscious? How did consciousness evolve? How does research on animal consciousness affect the ethical treatment of animals? What is the impact of issues about animal consciousness on theories of consciousness and vice versa? What are the best methods for assessing consciousness in nonhuman animals?

\section{Speakers and panelists include:}

Colin Allen (University of Pittsburgh, Department of History \& Philosophy of Science), Andrew Barron (Macquarie, Cognitive Neuroethology),

Victoria Braithwaite (Penn State, Biology), Peter Carruthers (Maryland,

Philosophy), Marian Dawkins (Oxford, Zoology), Dan Dennett (Tufts,

Philosophy), David Edelman (San Diego, Neuroscience),

Todd Feinberg (Mt. Sinai, Neurology), Peter Godfey-Smith (Sydney,

Philosophy), Lori Gruen (Wesleyan, Philosophy), Brian Hare (Duke, Evolutionary

Anthropology), Stevan Harnad (Montreal, Cognitive Science), Eva Jablonka (Tel

Aviv, Cohn Institute), Björn Merker (Neuroscience), Diana Reiss (Hunter,

Psychology), Peter Singer (Princeton, Philosophy), Michael Tye (Texas, Philosophy)

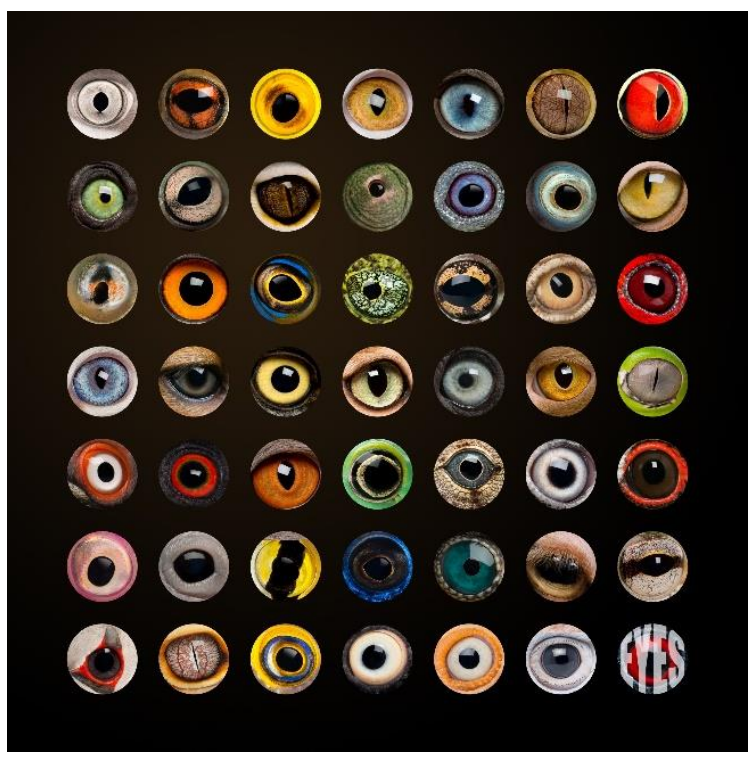

Organizers: Ned Block, David Chalmers, Dale Jamieson, S. Matthew Liao.

The conference will run from 9am on Friday November 17 to $6 \mathrm{pm}$ on Saturday November 18 at the NYU Cantor Film Center (36 E 8th St).

Friday sessions will include "Invertebrates and the evolution of consciousness", "Do fish feel pain?", and "Animal consciousness and ethics".

Saturday sessions will include "Animal self-consciousness", "Animal consciousness and theories of consciousness", and a panel discussion.

A detailed schedule will be circulated closer to the conference date.

Registration is free but required.

\section{Register here.}

\section{See also the conference website}

